\title{
Surface Modification of Porous Titanium with Microarc Oxidation and Its Effects on Osteogenesis Activity In Vitro
}

\author{
Qi Wang, ${ }^{1}$ Mengqi Cheng, ${ }^{1}$ Guo He, ${ }^{2}$ and Xianlong Zhang ${ }^{1}$ \\ ${ }^{1}$ Department of Orthopaedic Surgery, Shanghai Jiao Tong University Affiliated Sixth People's Hospital, Shanghai 200233, China \\ ${ }^{2}$ State Key Laboratory of Metal Matrix Composites, School of Materials Science and Engineering, \\ Shanghai Jiao Tong University, Shanghai 200240, China
}

Correspondence should be addressed to Guo He; ghe@sjtu.edu.cn and Xianlong Zhang; zhangxianlong6412@163.com

Received 1 December 2014; Revised 24 January 2015; Accepted 24 January 2015

Academic Editor: Donglu Shi

Copyright (C) 2015 Qi Wang et al. This is an open access article distributed under the Creative Commons Attribution License, which permits unrestricted use, distribution, and reproduction in any medium, provided the original work is properly cited.

\begin{abstract}
Microarc oxidation (MAO) is a method about surface treatment that can provide nanoporous pits and thick oxide layers. A kind of porous metal-entangled titanium $(\mathrm{Ti})$ wire material was treated with $\mathrm{MAO}$ process, resulting in a homogeneous rough $\mathrm{TiO}_{2}$ layer, which helped facilitate MG-63 cell growth, cell viability, early cell differentiation, and cell mineralization in vitro. In addition, the MAO-treated Ti surfaces could promote the proliferation of MG-63 cells without sacrificing differentiation in vitro, which would benefit de novo bone formation around MAO-treated titanium at the early stage. The transcription levels of the extracellular matrix genes of osterix (OSX), collagen type I (Col I), bone sialoprotein (BSP), alkaline phosphatase (ALP), osteocalcin (OC) and osteopontin (OPN) and their protein expression levels were measured, suggesting that the cocultured cells with MAO titanium maintained the osteoblastic phenotype and that the MAO-treated titanium surface greatly stimulated osteoblast cell proliferation and differentiation compared to the untreated titanium. In conclusion, MAO technique can improve the surface of titanium and can contribute to the osseointegration process.
\end{abstract}

\section{Introduction}

A number of surgical implants have shown the ability to induce bone formation, of which the success or failure of surgical implants can be related to chemical and biological properties of their surfaces as well as to their micromorphology $[1,2]$; that is, the implant surface plays an important role in the bone repair [3]. Part of the reason is the differences in the microstructure of implant surfaces that influence stress distribution, bone retention, and cellular response on its surface $[4,5]$. In recent years, porous implants have been developed in bone repairing [6] although the ideal porous requirements for surgical implants have not yet been reached [7]. The most used ideal biomaterial for fabrication of surgical implants is porous titanium (Ti) thanks to its excellent physicochemical properties, biocompatibility, resistance to corrosion, and acceptability by human tissues $[8,9]$.

The biomaterial-bone tissue interface is one of the key factors in that it would promote a better tissue response and it would be adequate for the proliferation of bone cells [10].
However, Porous Ti without any surface treatment is bioinert [11], so it has to have surface modification for implant fixation by tissue ingrowth [12]. The surface modification can bring a formation of a stable and protective layer of titanium dioxide $\left(\mathrm{TiO}_{2}\right)$ [13] that avoids direct contact between the implants and its milieu and also reduces the reactivity of the metal [14, 15]. The $\mathrm{TiO}_{2}$ layer can aid in connecting extracellular matrix to the implant surface [8], that is, to improve the biocompatibility of titanium. Up to now, there are various types of surface modification methods that have been explored to determine the optimum surface to further improve the bioactivity and biocompatibility of titanium [16]. Jäger et al. [17, 18] reported that the modification of the surface at the micronanoscale level is generally considered to be more conducive to the attachment, spread, and proliferation of osteoblast-like cells.

Microarc oxidation (MAO), also known as plasma electrolytic oxidation (PEO), is an electrochemical surface treatment process for generating oxide coatings on metals. MAO is similar to anodizing, but it employs higher potentials, so that discharges occur and the resulting plasma modifies 
the structure of the oxide layer to present high hardness to protect against wear and corrosion [19]. MAO also provides nanoporous pits and the incorporation of calcium and phosphorus into the biocompatible $\mathrm{TiO}_{2}$ coating layer which results in improved osteoblast cell responses [20, 21]. Therefore, the purpose of present study was to treat the pure Ti with MAO method to have nanoporous $\mathrm{TiO}_{2}$ surface and to investigate its effects on osteogenesis activity.

\section{Materials and Methods}

2.1. Microarc Oxidation of Porous Titanium. A kind of porous metal-entangled titanium wire (porosity, $44.7 \%$; yield strength, $75 \mathrm{MPa}$; tensile strength, $108 \mathrm{MPa}$; elastic modulus, 1.05 GPa) [22] (State Key Laboratory of Metal Matrix Composites, Shanghai Jiaotong University) was used as base material in this study. The titanium surface was ultrasonically cleaned with acetone, absolute ethanol, and distilled water for $15 \mathrm{~min}$ in series and then was treated by MAO in an aqueous electrolyte solution containing 3.5\% glycerophosphate disodium salt pentahydrate and $1.2 \%$ calcium acetate monohydrate (voltage: $350 \mathrm{~V}$, frequency: $800 \mathrm{~Hz}$ ) for 30 seconds and again ultrasonically rinsed with distilled water for $15 \mathrm{~min}$.

\subsection{Ti Morphology and Chemical Composition Characteri-} zation. The surface morphology and chemical composition of the untreated and treated titanium wires were studied by scanning electron microscopy (SEM) with electron diffraction X-ray (EDX) system by FEI Nova NanoSEM230 scanning electron microscope.

2.3. Cell Culture. MG63 cells (Institute of Biochemistry and Cell Biology, SIBS, CAS), a line derived from a human osteosarcoma, were incubated with standard DMEM culture medium containing $10 \%(\mathrm{v} / \mathrm{v})$ fetal bovine serum (Invitrogen), $100 \mathrm{U} / \mathrm{mL}$ penicillin, and $0.1 \mathrm{mg} / \mathrm{mL}$ streptomycin at $37^{\circ} \mathrm{C}$ in a humidified atmosphere of $95 \%$ air and $5 \%$ $\mathrm{CO}_{2}$. Cells at passage 2 or 3 were used for the following experiments. Cells were randomly divided into MAO group and control group, and each experiment was repeated 3 times.

2.4. Cell Morphology Observation. $1 \times 10^{4}$ cells/well was incubated with sterilized MAO titanium in a 24-well plate for one day, and then the MAO titanium with or without cells was observed by FEI Nova NanoSEM230 scanning electron microscope.

2.5. Cell Proliferation. The proliferation of MG63 cells was evaluated using a cell counting kit-8 (CCK-8) assay (Dojindo, Japan). $1 \times 10^{4}$ cells/well was incubated with sterilized MAO titanium in a 24 -well plate under normal conditions for eight hours. After that, the samples were moved to a new 24-well plate (500 $\mu \mathrm{L}$ per well) to culture for $1,4,8$, and 16 days, and then $50 \mu \mathrm{L}$ CKK-8 solution was added to each well for $4 \mathrm{~h}$. $100 \mu \mathrm{L}$ of the supernatants was transferred to a 96-well plate and the optical density was determined using a microtiter plate reader (Thermo LabSystems) at $450 \mathrm{~nm}$.
2.6. Alkaline Phosphatase Assay. The alkaline phosphatase activity was determined by Alkaline Phosphatase Assay Kit (Abcam, USA), following the manufacturer's protocol. In brief, $1 \times 10^{4}$ cells/well was incubated with sterilized MAO titanium in a 24-well plate under normal conditions for eight hours, and then the samples were moved to a new 24-well plate and to culture for $1,4,8$, and 16 days. The harbored cells were homogenized with $100 \mu \mathrm{L}$ assay buffer after cold PBS washing. For each sample, $80 \mu \mathrm{L}$ of supernatant was transferred into a 96-well plate, followed by adding $20 \mu \mathrm{L}$ of stop solution for all reactions. Standard curves were generated as manufacture's guide. The alkaline phosphatase enzyme activity of each sample was calculated based on the comparison between standard curve and sample curve and was shown as Unit/mL (U/mL).

2.7. Measurement of Intracellular $\mathrm{Ca}^{2+}$. Intracellular $\mathrm{Ca}^{2+}$ levels were determined with a Becton Dickinson FACSCalibur flow cytometer. Cells were incubated with $3 \mathrm{uM}$ Fluo3/AM dye at $37^{\circ} \mathrm{C}$ for $30 \mathrm{~min}$ in the dark. After gently rinsed three times with D-Hanks' solution, cells were resuspended in Krebs-Ringer-HEPES (KRH) buffer. The fluorescence was analyzed by flow cytometry with excitation and emission wavelengths of $488 \mathrm{~nm}$ and $526 \mathrm{~nm}$ every one minute.

2.8. Western Blotting. $1 \times 10^{4}$ cells/well was incubated with sterilized MAO titanium in a 24 -well plate under normal conditions for eight hours, and then the samples were moved to a new 24-well plate to culture for $1,4,8$, and 16 days. The total protein was extracted from the cells using $\mathrm{M}$ PER mammalian protein extraction reagent (Pierce, USA). Equal amounts of protein (10 $\mu \mathrm{g}$ per lane) estimated by a bicinchoninic acid (BCA) protein assay kit (Pierce, USA) were separated by sodium dodecyl sulfate polyacrylamide gel electrophoresis (SDS-PAGE) and transferred onto nitrocellulose membranes and immunoblotting was performed using primary antibodies (Santa Cruz, USA), beta actin (1:800), OSX (1:500), OC $(1: 600)$, collagen I $(1: 300)$, OPN $(1: 500)$, and BSP $(1: 400)$. Antibodies were visualized using secondary HRP-conjugated anti-mouse/anti-rabbit antibody (CST, USA). After washing, the bands were detected by chemiluminescence (ECL detection kit) and imaged with Xray films. Beta actin was used as an endogenous reference for normalization.

2.9. Quantitative Real-Time Polymerase Chain Reaction. The cells were treated according to the procedure described above. Total RNA samples were prepared from MG63 cells using Trizol (Invitrogen, USA) according to the manufacturer's instruction and reversely transcribed into cDNA using MMLV reverse transcriptase (Takara BIO, Japan) and oligo (dT) 18 primer (Takara BIO). Quantitative real-time polymerase chain reaction (qRT-PCR) was performed by using a SYBR premix Ex Taq kit (Takara BIO) and TP800 system (Takara BIO). DNA from $500 \mathrm{ng}$ total RNA was used as the template. The PCR reactions were carried out under the following conditions: 40 cycles of denaturation at $95^{\circ} \mathrm{C}$ for $10 \mathrm{~s}$, annealing at $60^{\circ} \mathrm{C}$ for $20 \mathrm{~s}$, and extension at $72^{\circ} \mathrm{C}$ for $20 \mathrm{~s}$. The primers 
TABLE 1: Primers used in quantitative real-time PCR.

\begin{tabular}{lll}
\hline Gene/GenBank number & Forward primer $\left(5^{\prime}-3^{\prime}\right)$ & Reverse primer $\left(5^{\prime}-3^{\prime}\right)$ \\
\hline Beta actin/NM_001101.3 & CCCAAGGCCAACCGCGAGAAGATG & GTCCCGGCCAGCCAGGTCCAGA \\
OSX/NM_001173467.1 & GCTGCCCACCTACCCATCTGACTT & CTGCCCCCATATCCACCACTACCC \\
ALP/NM_014476.5 & GACAATCGGAATGAGCCCACAC & GTACTTATCCCGCGCCTTCACCAC \\
Collagen I/NM_000088.3 & ACCTCCGGCTCCTGCTCCTCTTAG & GCGCCGGGGCAGTTCTTGGTCT \\
OC/NM_199173.4 & AGCCCAGCGGTGCAGAGTCCA & GCCGTAGAAGCGCCGATAGG \\
OPN/NM_001040058.1 & TCTGATGAATCTGATGAACTGGTC & GGTGATGTCCTCGTCTGTAGCA \\
BSP/NM_004967.3 & AAGAAGGGGAAGAAGAAAGTGTCA & GTATTCATTGGCGCCCGTGTATTC \\
\hline
\end{tabular}

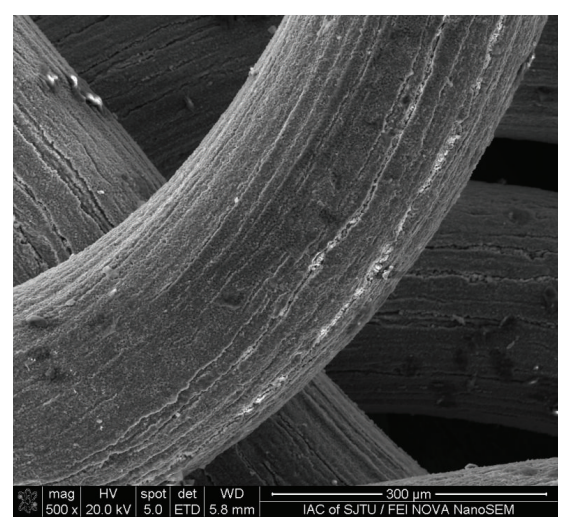

(a1)

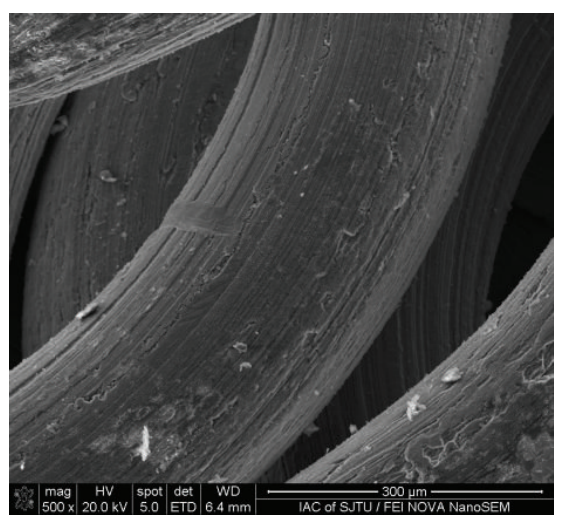

(b1)

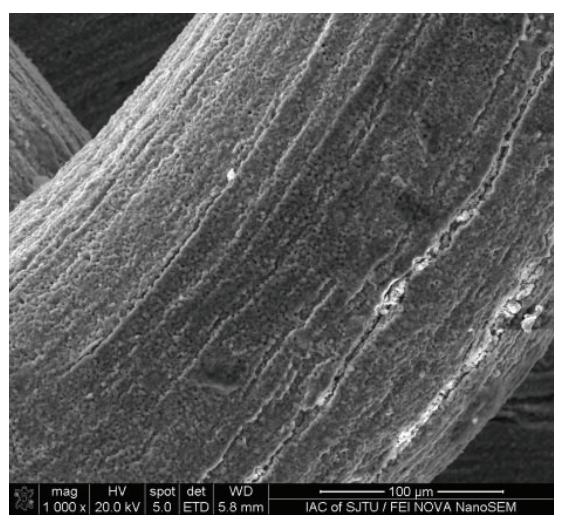

(a2)

(a)

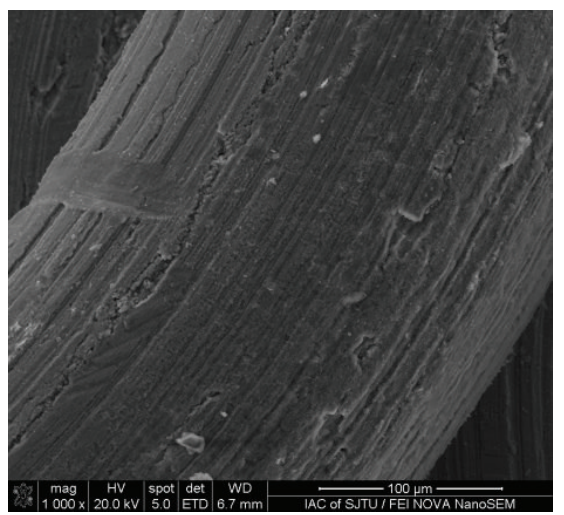

(b2)

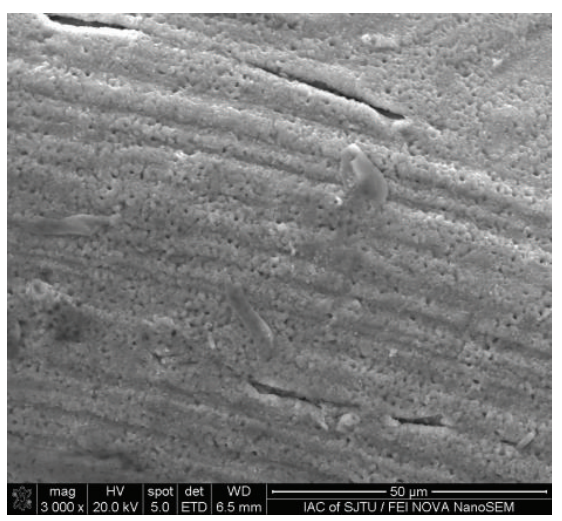

(a3)

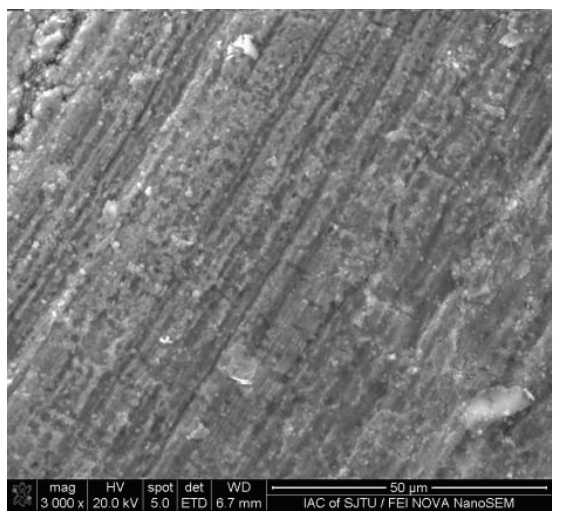

(b3)

(b)

FIGURE 1: SEM images of Ti samples before and after MAO process. (a) MAO titanium surface ((a1) 500x; (a2) 1000x; (a3) 3000x); (b) untreated titanium surface ((b1) 500x; (b2) 1000x; (b3) 3000x).

were listed in Table 1. Relative quantifications were calculated with the $2^{-\Delta \Delta \mathrm{Ct}}$ method. Beta actin was used as housekeeping genes, due to its unchanged expression during treatment.

2.10. Statistical Analysis. Quantitative data were expressed as the mean \pm sd. Statistical analysis was conducted using the two-sample $t$-test. A value of $P<0.05$ was considered to be statistically significant.

\section{Results}

3.1. Surface Analysis of Ti Samples before and after MAO Process. Figure 1 presents the SEM images of the morphology and microstructure of the samples. A homogeneous rough appearance could be seen on the surface of the MAO porous titanium sample (Figure 1(a)). Under higher magnification, a porous structure, in which grain and pore sizes were in 


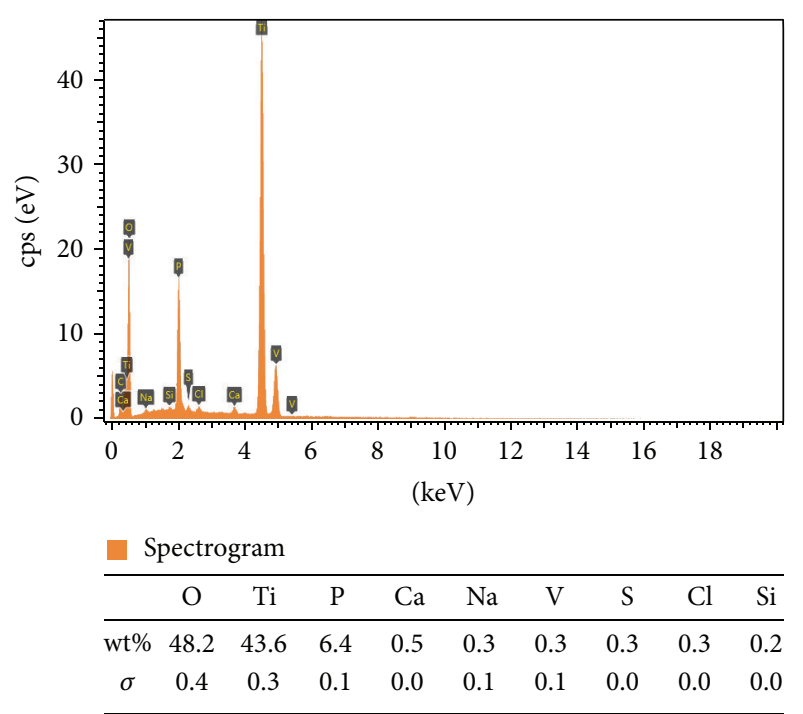

(a)

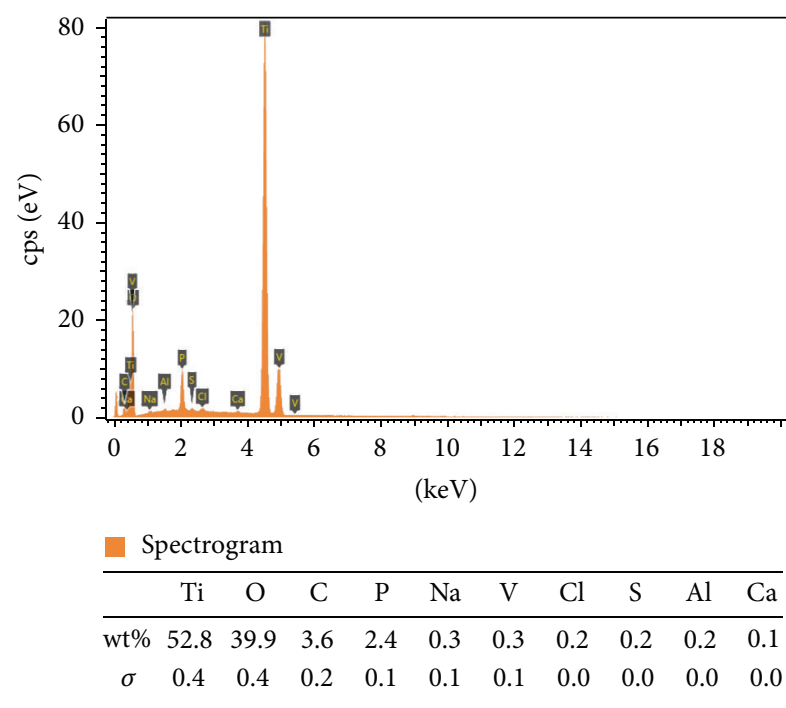

(b)

FIGURE 2: EDX micrographs of the Ti samples before and after MAO process. (a) MAO titanium surface; (b) untreated titanium surface.

nanoscale, formed by partially melted particles, was observed on the titanium wire surfaces. Compared to MAO process porous titanium sample, the appearance of untreated titanium porous samples (Figure 1(b)) exhibited a relatively smooth surface with some pits; no nanoscaled grains could be observed on their surfaces, which represented the typical morphology of native oxide film, with thin and nonporous structure. Figure 2 presented the energy dispersive X-ray (EDX) spectrum of untreated and treated titanium samples, which indicated that they formed a rough $\mathrm{TiO}_{2}$ layer on the MAO-treated titanium surface compared to the untreated $\mathrm{Ti}$ surface. The surface chemical characterization also showed higher peaks of calcium and phosphate on the MAO-treated titanium surface compared to the untreated Ti surface.

3.2. Cell Morphology on Ti Surface. The morphology of the MG-63 cells cultured on the titanium surfaces with or without MAO process for 24 hours is shown in Figure 3. MG-63 cells were found growing on the titanium surfaces; in addition, there were more cells adhered to the MAO-treated surface than to the untreated Ti surface. The majority of the cells displayed a similar morphology and showed some slender filopodia or lamellipodia.

3.3. Assessment of Cell Proliferation. MG-63 cells proliferation was assessed using CCK-8 assay. As shown in Figure 4, the cell proliferation increased over time on the different surfaces. No significant differences were found among the samples at day 1 and day 4 , but at day 8 and day 16 there were significant differences $(P<0.05$ or $<0.01)$ between the two groups, suggesting that anodization facilitates cell growth and can promote cell viability.

3.4. Alkaline Phosphatase Activity. Alkaline phosphatase activity is an indicator of early osteogenic cell differentiation, bone formation, and matrix mineralization [23]. As shown in Figure 5, the ALP activities for the two samples increased with time, and at day 8 and day 16 there were significant differences $(P<0.05$ or $P<0.01)$ between them, suggesting that MAO facilitates early cell differentiation and bone formation.

3.5. Intracellular $\mathrm{Ca}^{2+}$ Assay. The intracellular $\mathrm{Ca}^{2+}$ levels at day 8 and day 16 were analyzed by flow cytometry (Figure 6). It was noted that the intracellular $\mathrm{Ca}^{2+}$ level in the experimental group significantly increased with time compared to that in the control group $(P<0.01)$, which suggested that MG-63 cells had definite osteoblastic phenotype to get mineralization on MAO-treated titanium surface.

3.6. Osteoblastic Phenotype Analysis. MG-63 cells were incubated with sterilized MAO titanium in a 24 -well plate for 1 , 4,8 , and 16 days, and these cocultured cells were found to express the transcripts for the extracellular matrix genes of OSX, Col I, BSP, ALP, OC. and OPN (Figure 7), the later and earlier markers of osteoblastic phenotype, based on the quantitative time-PCR results. The OSX, Col I, BSP, OC, and OPN protein expression (Figure 8) were further confirmed with western blotting, which suggested that the cocultured cells with MAO titanium maintained the osteoblastic phenotype. Moreover, the expression levels demonstrated differences between two groups, which suggested that the MAOtreated titanium surface greatly stimulated osteoblast cell proliferation and differentiation compared to the untreated titanium.

\section{Discussion}

Commercial pure titanium and its alloys are considered ideal materials because they have shown better acceptability by human tissues than other metals under diverse circumstances 


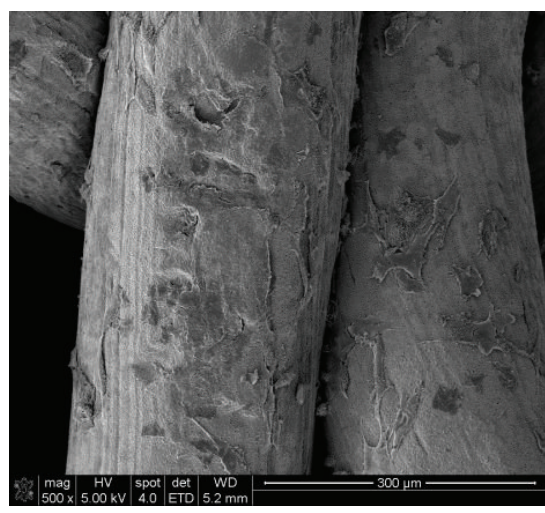

(a1)

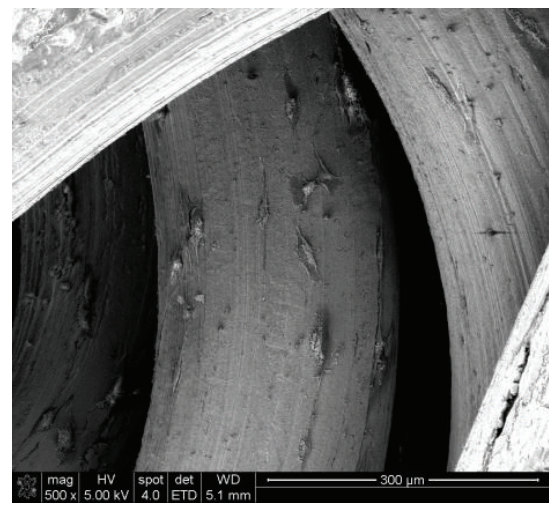

(b1)

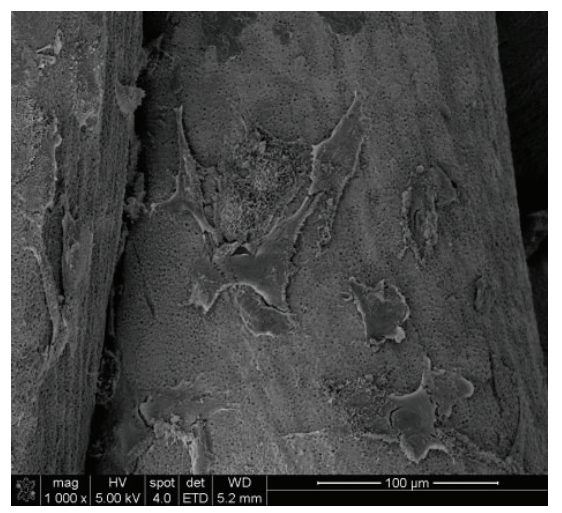

(a2)

(a)

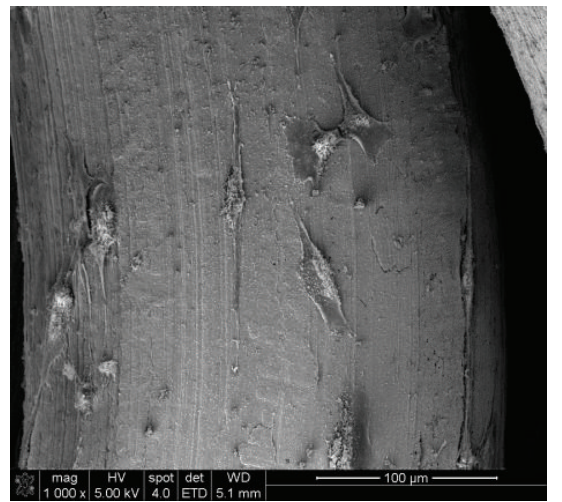

(b2)

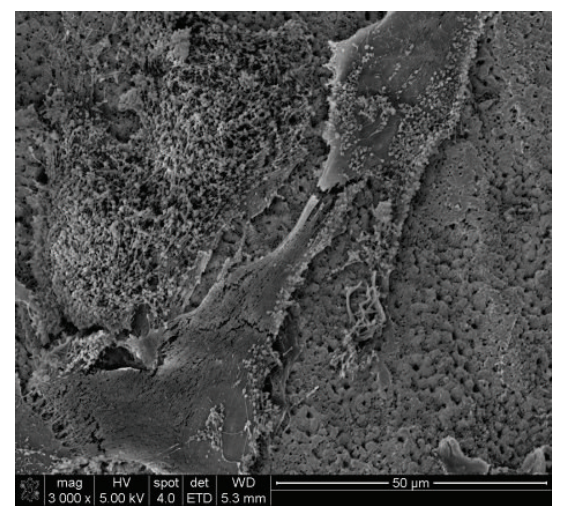

(a3)

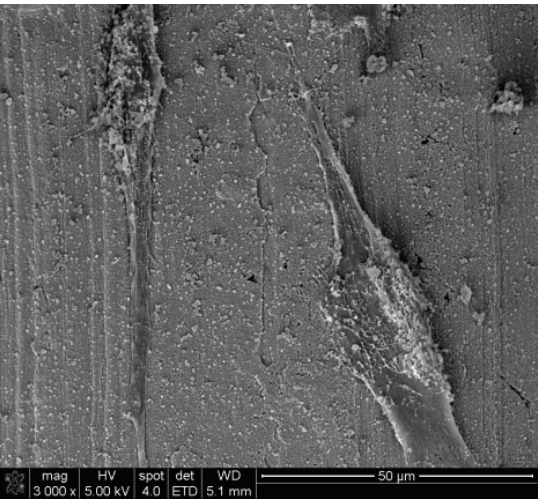

(b3)

(b)

FIGURE 3: SEM images of the titanium surfaces with or without MAO process after coculture with MG-63 cells. (a) MAO titanium surface ((a1) 500x; (a2) 1000x; (a3) 3000x); (b) untreated titanium surface ((b1) 500x; (b2) 1000x; (b3) 3000x).

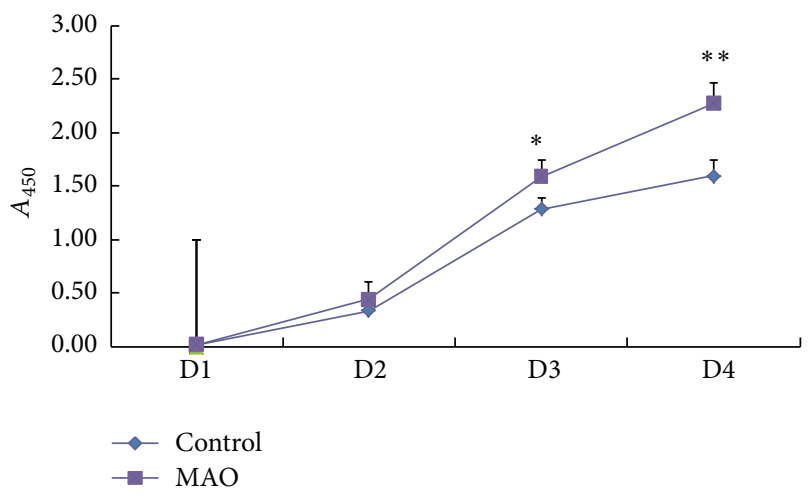

Figure 4: The cell viability was measured by the CCK- 8 assay versus control, ${ }^{*} P<0.05 ;{ }^{* *} P<0.01$.

due to their excellent mechanical properties, biocompatibility, and resistance to corrosion $[8,9,24]$. However, titanium implant failures still remain in some cases [25], and this is partly because Ti without any surface treatment is bioinert. In fact, surface chemistry, roughness, and topography are all

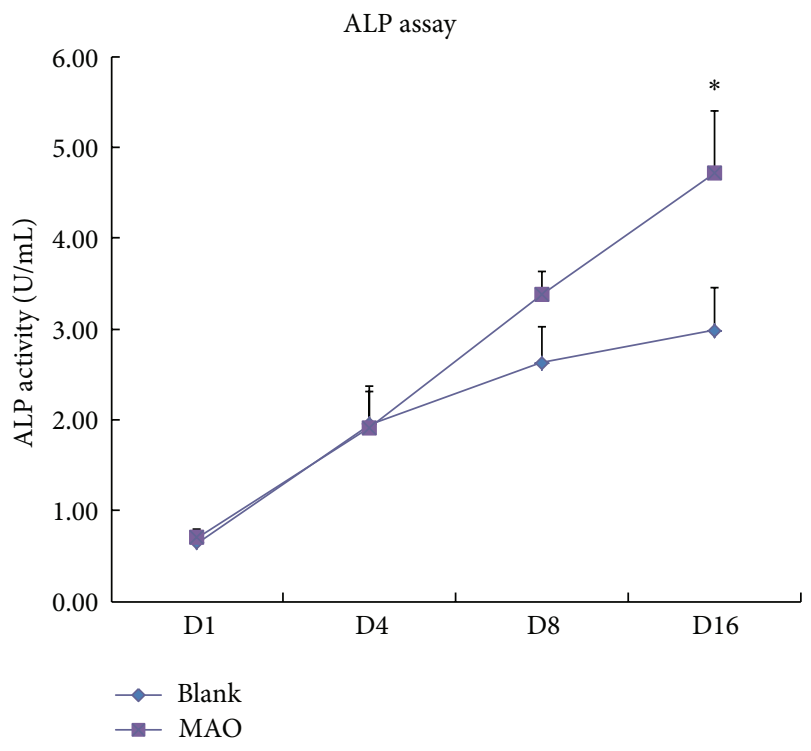

FIGURE 5: ALP activity of MG-63 cells on the titanium surfaces with or without MAO process. ${ }^{*} \mathrm{P}<0.05$. 

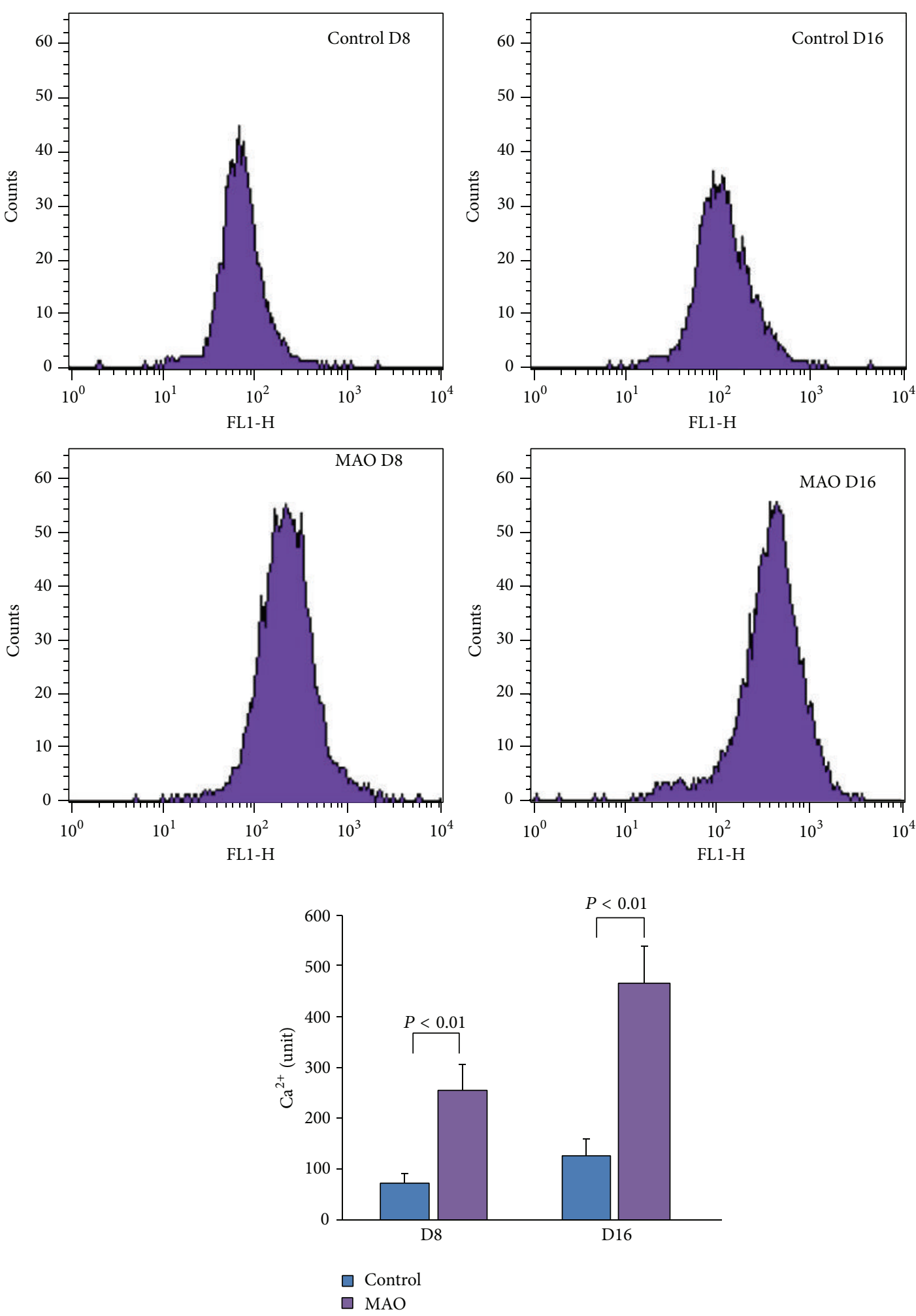

FIGURE 6: Intracellular $\mathrm{Ca}^{2+}$ of MG-63 cells on the titanium surfaces with or without MAO process.

parameters that influence both the osseointegration and biocompatibility [26]. Hence, some types of surface modification method have been explored to further improve the bioactivity and biocompatibility of Ti and minimize the risk of implant failures [16].
MAO is a promising technology that can produce porous, rough, and firmly adherent $\mathrm{TiO}_{2}$ coatings on titanium surfaces [27]. It is well known that $\mathrm{TiO}_{2}$ is an attractive semiconductor for certain photocatalytic applications, such as decontamination and bactericidal effects. In addition, $\mathrm{TiO}_{2}$ 
OSX/actin

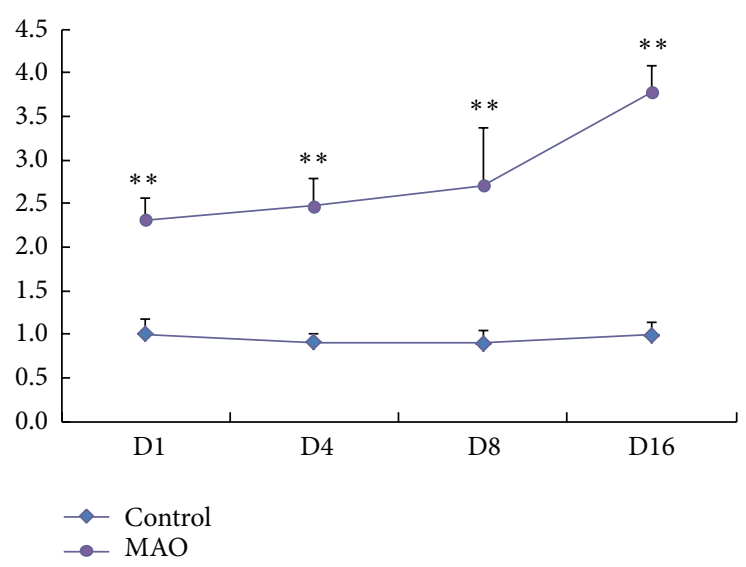

BSP/actin

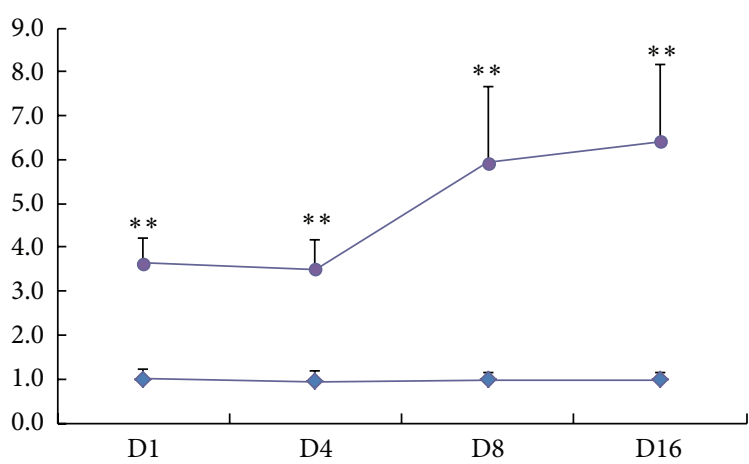

$\rightarrow$ Control

$\rightarrow$ MAO

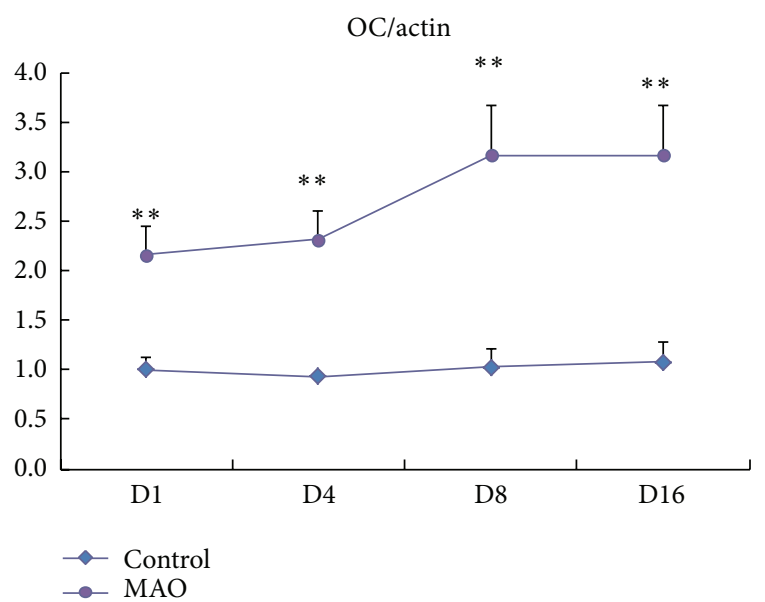

COL I/actin

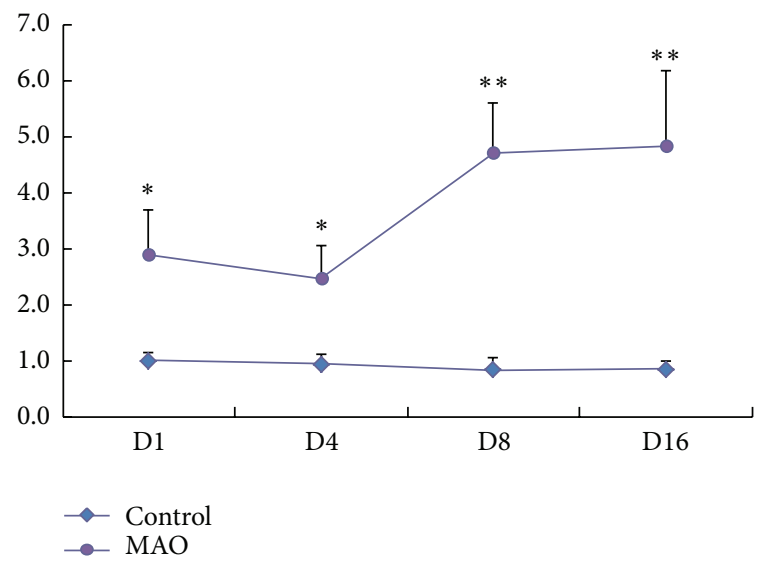

ALP/actin

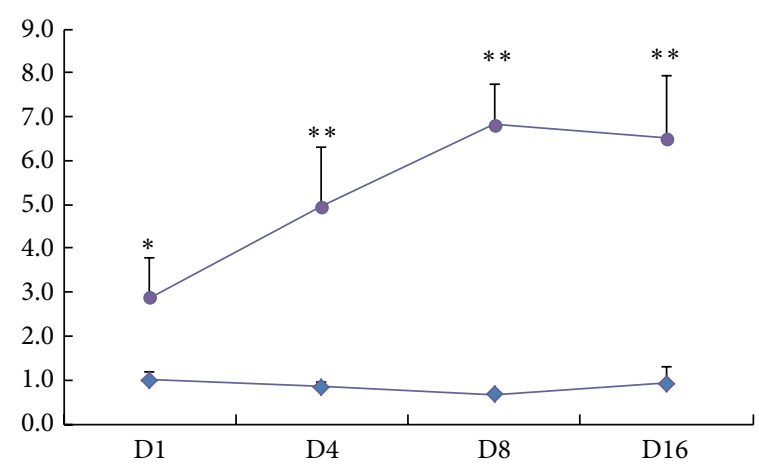

$\neg$ Control

- MAO

OPN/actin

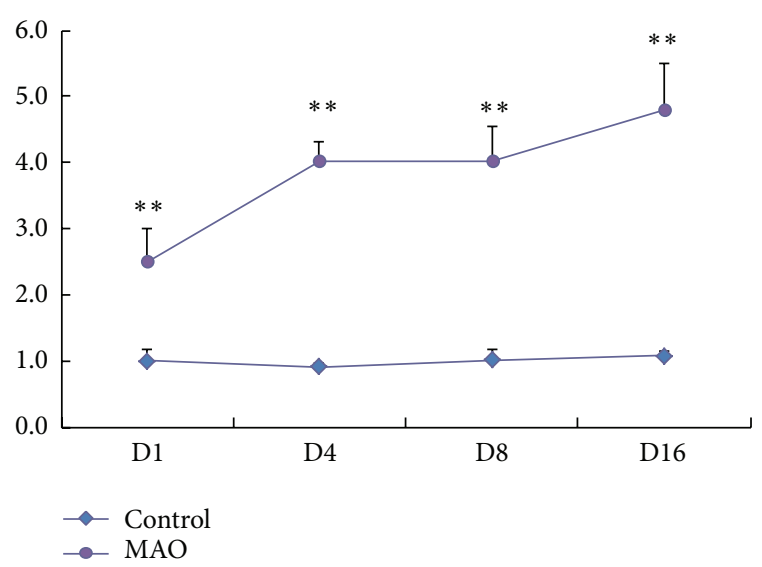

FIgURE 7: The quantitative time-PCR results versus control on the same day. ${ }^{*} P<0.05$; ${ }^{* *} P<0.01$. OSX, osterix; COL I, type I collagen; BSP, bone sialoprotein; ALP, alkaline phosphatase activity; OC, osteocalcin; OPN, osteopontin.

could help increase incorporates calcium or phosphorus ions into the surface layer and is beneficial to osteoblastic cell activity. In this paper, the titanium treated with MAO was a kind of porous metal-entangled titanium wire material [22], of which the porosity, yield strength, ultimate tensile strength, and elastic modulus are $44.7 \%, 75 \mathrm{MPa}, 108 \mathrm{MPa}$, and $1.05 \mathrm{GPa}$, respectively. This kind of material is very promising for implant applications because of their very good toughness, perfect flexibility, high strength, adequate elastic modulus, and low cost [22].

MAO-treated titanium surface showed a homogeneous rough $\mathrm{TiO}_{2}$ layer on it (Figure 1(a)) compared to the untreated Ti surface; in fact, the roughness $\mathrm{TiO}_{2} / \mathrm{Ti}$ surface is better than the smooth for biocompatibility. With further studies, 

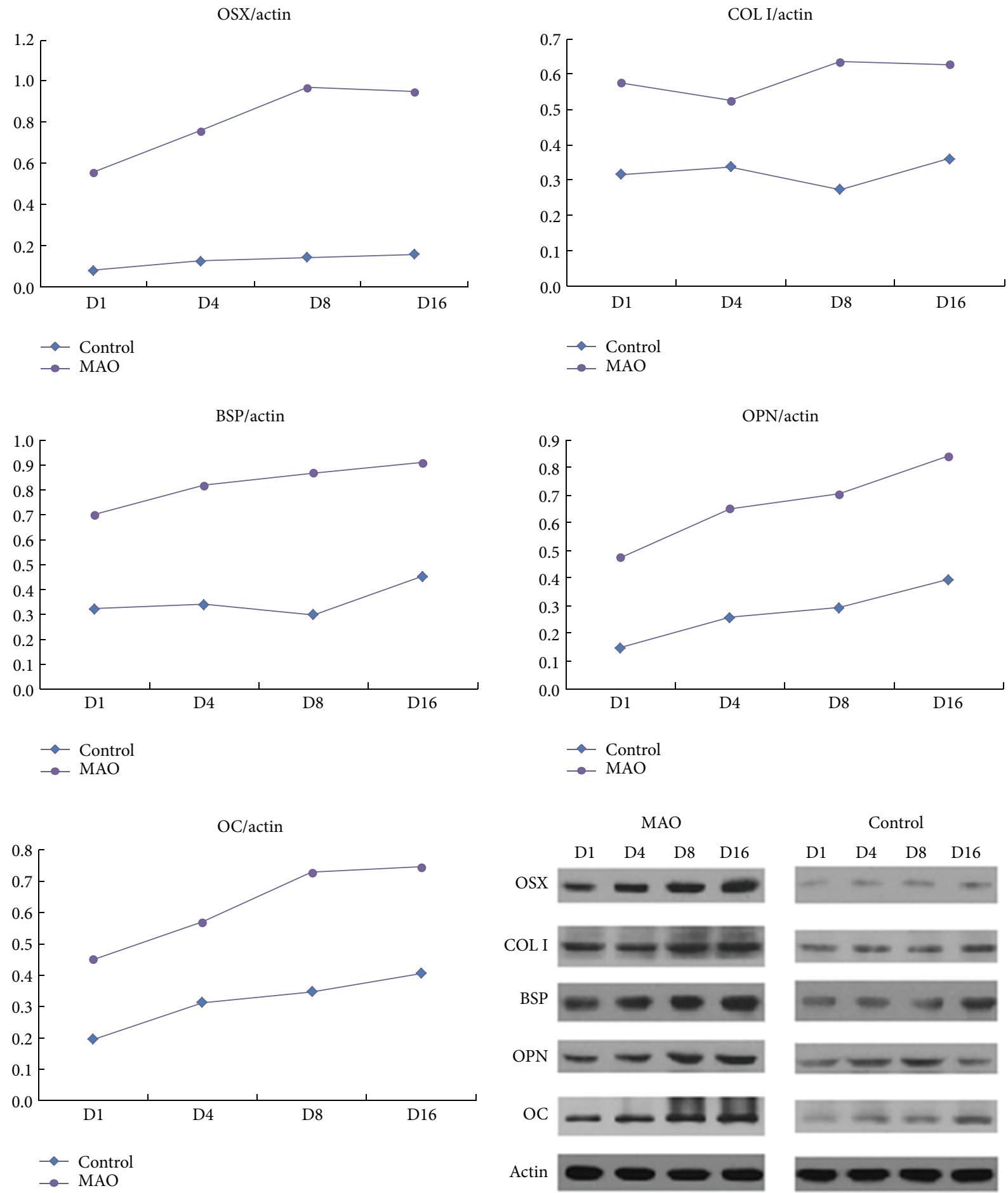

FIGURE 8: The western blotting results. OSX, osterix; COL I, type I collagen; BSP, bone sialoprotein; OC, osteocalcin; OPN, osteopontin.

we found that there were more MG-63 cells adhered to the rougher surface, and the cck-8 test and ALP assay suggested that MAO-treated outfaces facilitate cell growth, cell viability, and early cell differentiation. Alborzi et al. [28, 29] reported that an inverted correlation exists between osteoblastic proliferation and differentiation; however, it was found in this paper that the MAO-treated Ti surfaces promote the proliferation of MG-63 cells without sacrificing differentiation, which would benefit de novo bone formation around MAOtreated titanium at the early stage. The intracellular $\mathrm{Ca}^{2+}$ level in the MAO-treated titanium group significantly increased with time compared to that in the control group $(P<0.01)$, 
suggesting that MG-63 cells had definite osteoblastic phenotype to get mineralization on MAO-treated titanium surface.

Biologic and morphologic responses to osteoblast cell lines (MG-63) were further examined by measuring the transcription levels for the extracellular matrix genes of osterix (OSX), collagen type I ( Col I), bone sialoprotein (BSP), alkaline phosphatase (ALP), osteocalcin (OC), and osteopontin (OPN) and their protein expression levels (Figures 7, 8, and 5). ALP, COL1, and OSX are known to be early markers of osteoblastic differentiation, whereas BSP, OC, and OPN are expressed later in the differentiation process [30]. These proteins of osteoblastic phenotype play major roles in osteoblast differentiation by promoting the differentiation of undifferentiated mesenchymal cells into osteoblasts [31, 32]. The results indicated that the cocultured cells with MAOtreated titanium maintained the osteoblastic phenotype and could greatly stimulated osteoblast cell proliferation and differentiation compared to the untreated titanium.

In conclusion, MAO technique can improve the surface of titanium and stimulates cell proliferation and early cell differentiation, which may provide a new approach to the osseointegration of surgical implants. On the other hand, we noted a limitation to this paper that this was a study in vitro on cells and MAO-treated titanium, so more studies are needed to determine the biocompatibility and the osseointegration in vivo.

\section{Conflict of Interests}

The authors declare that there is no conflict of interests regarding the publication of this paper.

\section{References}

[1] O. Zinger, G. Zhao, Z. Schwartz et al., "Differential regulation of osteoblasts by substrate microstructural features," Biomaterials, vol. 26, no. 14, pp. 1837-1847, 2005.

[2] M. Svehla, P. Morberg, B. Zicat, W. Bruce, D. Sonnabend, and W. R. Walsh, "Morphometric and mechanical evaluation of titanium implant integration: comparison of five surface structures," Journal of Biomedical Materials Research, vol. 51, no. 1, pp. 15-22, 2000.

[3] L. F. Cooper, "Biologic determinants of bone formation for osseointegration: clues for future clinical improvements," The Journal of Prosthetic Dentistry, vol. 80, no. 4, pp. 439-449, 1998.

[4] M. V. Oliveira, L. C. Pereira, and C. A. A. Cairo, "Porous structure characterization in titanium coating for surgical implants," Materials Research, vol. 5, no. 3, pp. 269-273, 2002.

[5] H. Q. Nguyen, D. A. Deporter, R. M. Pilliar, N. Valiquette, and R. Yakubovich, "The effect of sol-gel-formed calcium phosphate coatings on bone ingrowth and osteoconductivity of poroussurfaced Ti alloy implants," Biomaterials, vol. 25, no. 5, pp. 865876, 2004.

[6] J. E. Ellingsen, "Surface configurations of dental implants," Periodontology 2000, vol. 17, no. 1, pp. 36-46, 1998.

[7] M. Ysander, R. Brånemark, K. Olmarker, and R. R. Myers, "Intramedullary osseointegration: development of a rodent model and study of histology and neuropeptide changes around titanium implants," Journal of Rehabilitation Research and Development, vol. 38, no. 2, pp. 183-190, 2001.
[8] D. G. Olmedo, G. Duffó, R. L. Cabrini, and M. B. Guglielmotti, "Local effect of titanium implant corrosion: an experimental study in rats," International Journal of Oral and Maxillofacial Surgery, vol. 37, no. 11, pp. 1032-1038, 2008.

[9] R. M. Wazen, L.-P. Lefebvre, E. Baril, and A. Nanci, "Initial evaluation of bone ingrowth into a novel porous titanium coating," Journal of Biomedical Materials Research, Part B: Applied Biomaterials, vol. 94, no. 1, pp. 64-71, 2010.

[10] R. K. Schenk and D. Buser, "Osseointegration: a reality," Periodontology 2000, vol. 17, no. 1, pp. 22-35, 1998.

[11] R. M. Pilliar, "Powder metal-made orthopedic implants with porous surface for fixation by tissue ingrowth," Clinical Orthopaedics and Related Research, no. 176, pp. 42-51, 1983.

[12] F. Togni, F. Baras, M. D. O. Ribas, and M. O. Taha, "Histomorphometric analysis of bone tissue repair in rabbits after insertion of titanium screws under different torque," Acta Cirurgica Brasileira, vol. 26, no. 4, pp. 235-241, 2011.

[13] R. L. Cabrini, M. B. Guglielmotti, and J. C. Almagro, "Histomorphometry of initial bone healing around zirconium implants in rats," Implant Dentistry, vol. 2, no. 4, pp. 264-267, 1993.

[14] S. Abramson, H. Alexander, S. Best, C. Bokros, and J. B. Brunski, "Classes of materials used in medicine," in Biomaterials Science, D. Buddy, B. D. Ratner, A. S. Hoffman, F. J. Schoen, and J. E. Lemons, Eds., pp. 67-233, Elsevier Academic Press, San Diego, Calif, USA, 2004.

[15] R. Adell, B. Eriksson, U. Lekholm, P. I. Brånemark, and T. Jemt, "Long-term follow-up study of osseointegrated implants in the treatment of totally edentulous jaws," The International Journal of Oral \& Maxillofacial Implants, vol. 5, no. 4, pp. 347-359, 1990.

[16] M. Roy, A. Bandyopadhyay, and S. Bose, "Induction plasma sprayed nano hydroxyapatite coatings on titanium for orthopaedic and dental implants," Surface and Coatings Technology, vol. 205, no. 8-9, pp. 2785-2792, 2011.

[17] M. Jäger, C. Zilkens, K. Zanger, and R. Krauspe, "Significance of nano- and microtopography for cell-surface interactions in orthopaedic implants," Journal of Biomedicine and Biotechnology, vol. 2007, Article ID 69036, 19 pages, 2007.

[18] T. Ueno, N. Tsukimura, M. Yamada, and T. Ogawa, "Enhanced bone-integration capability of alkali- and heat-treated nanopolymorphic titanium in micro-to-nanoscale hierarchy," Biomaterials, vol. 32, no. 30, pp. 7297-7308, 2011.

[19] J. A. Curran and T. W. Clyne, "Thermo-physical properties of plasma electrolytic oxide coatings on aluminium," Surface and Coatings Technology, vol. 199, no. 2-3, pp. 168-176, 2005.

[20] F. Liu, Y. Song, F. Wang, T. Shimizu, K. Igarashi, and L. Zhao, "Formation characterization of hydroxyapatite on titanium by microarc oxidation and hydrothermal treatment," Journal of Bioscience and Bioengineering, vol. 100, no. 1, pp. 100-104, 2005.

[21] Y. W. Lim, S. Y. Kwon, D. H. Sun, H. E. Kim, and Y. S. Kim, "Enhanced cell integration to titanium alloy by surface treatment with microarc oxidation: a Pilot Study," Clinical Orthopaedics and Related Research, vol. 467, no. 9, pp. 22512258, 2009.

[22] G. He, P. Liu, and Q. Tan, "Porous titanium materials with entangled wire structure for load-bearing biomedical applications," Journal of the Mechanical Behavior of Biomedical Materials, vol. 5, no. 1, pp. 16-31, 2012.

[23] L. Le Guéhennec, A. Soueidan, P. Layrolle, and Y. Amouriq, "Surface treatments of titanium dental implants for rapid osseointegration," Dental Materials, vol. 23, no. 7, pp. 844-854, 2007. 
[24] M. Schuier, Q. Trentin, M. Textor, and S. G. P. Tosatti, "Biomedical interfaces: titanium surface technology for implants and cell carriers," Nanomedicine, vol. 1, no. 4, pp. 449-463, 2006.

[25] J. T. Steigenga, K. F. al-Shammari, F. H. Nociti, C. E. Misch, and H.-L. Wang, "Dental implant design and its relationship to longterm implant success," Implant Dentistry, vol. 12, no. 4, pp. 306317, 2003.

[26] A. Shenhar, I. Gotman, E. Y. Gutmanas, and P. Ducheyne, "Surface modification of titanium alloy orthopaedic implants via novel powder immersion reaction assisted coating nitriding method," Materials Science and Engineering A, vol. 268, no. 1-2, pp. 40-46, 1999.

[27] K. B. Sagomonyants, M. Hakim-Zargar, A. Jhaveri, M. S. Aronow, and G. Gronowicz, "Porous tantalum stimulates the proliferation and osteogenesis of osteoblasts from elderly female patients," Journal of Orthopaedic Research, vol. 29, no. 4, pp. 609-616, 2011.

[28] A. Alborzi, K. Mac, C. A. Glackin, S. S. Murray, and J. H. Zernik, "Endochondral and intramembranous fetal bone development: osteoblastic cell proliferation, and expression of alkaline phosphatase, m-twist, and histone H4," Journal of Craniofacial Genetics and Developmental Biology, vol. 16, no. 2, pp. 94-106, 1996.

[29] G. Y. Di Veroli, M. R. Davies, H. Zhang, N. Abi-Gerges, and M. R. Boyett, "High-throughput screening of drug-binding dynamics to HERG improves early drug safety assessment," American Journal of Physiology: Heart and Circulatory Physiology, vol. 304, no. 1, pp. H104-H117, 2013.

[30] M. W. Long, "Osteogenesis and bone-marrow-derived cells," Blood Cells, Molecules, and Diseases, vol. 27, no. 3, pp. 677-690, 2001.

[31] T. Komori, "Regulation of skeletal development by the Runx family of transcription factors," Journal of Cellular Biochemistry, vol. 95, no. 3, pp. 445-453, 2005.

[32] H. Harada, S. Tagashira, M. Fujiwara et al., "Cbfal isoforms exert functional differences in osteoblast differentiation," The Journal of Biological Chemistry, vol. 274, no. 11, pp. 6972-6978, 1999. 

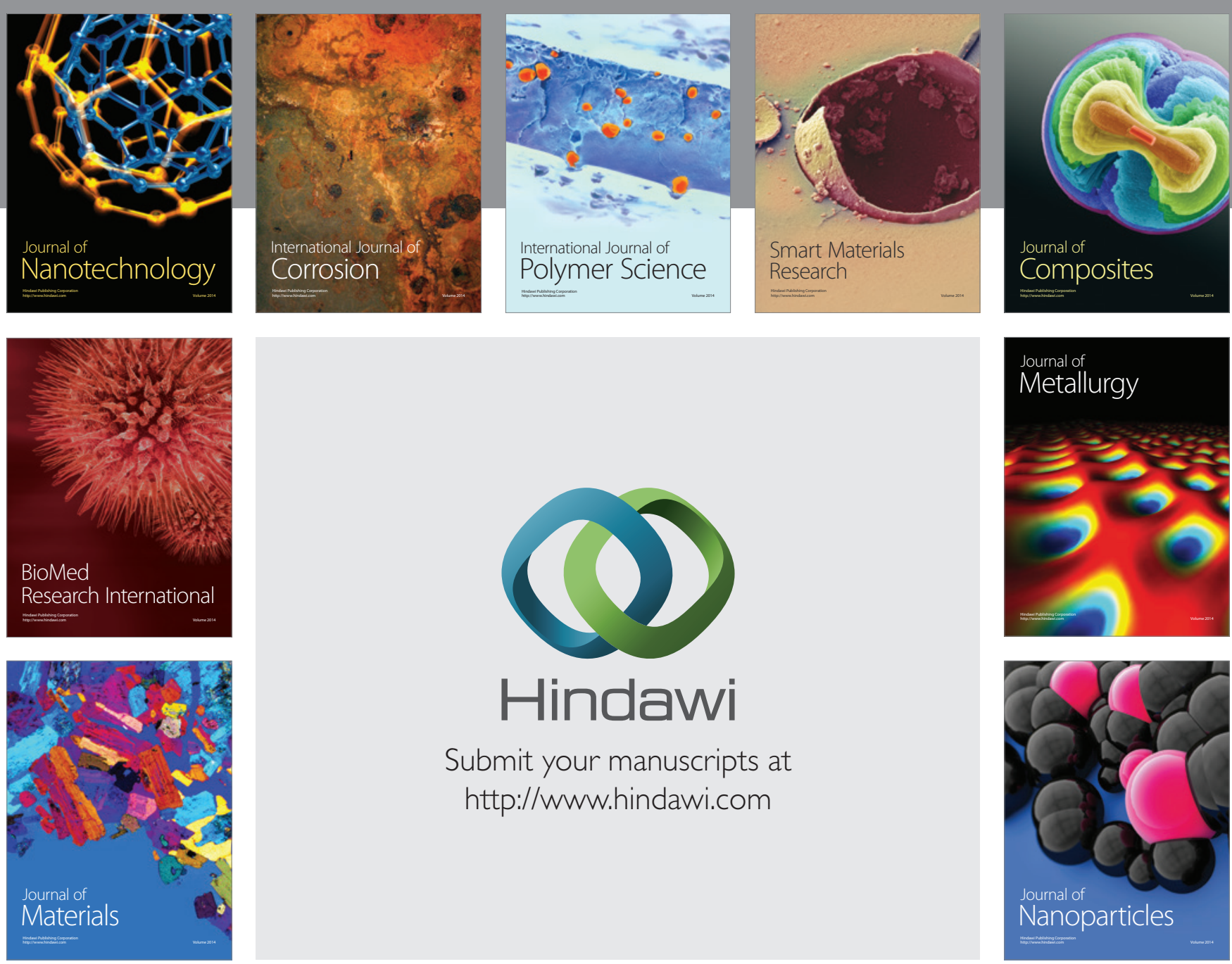

Submit your manuscripts at http://www.hindawi.com
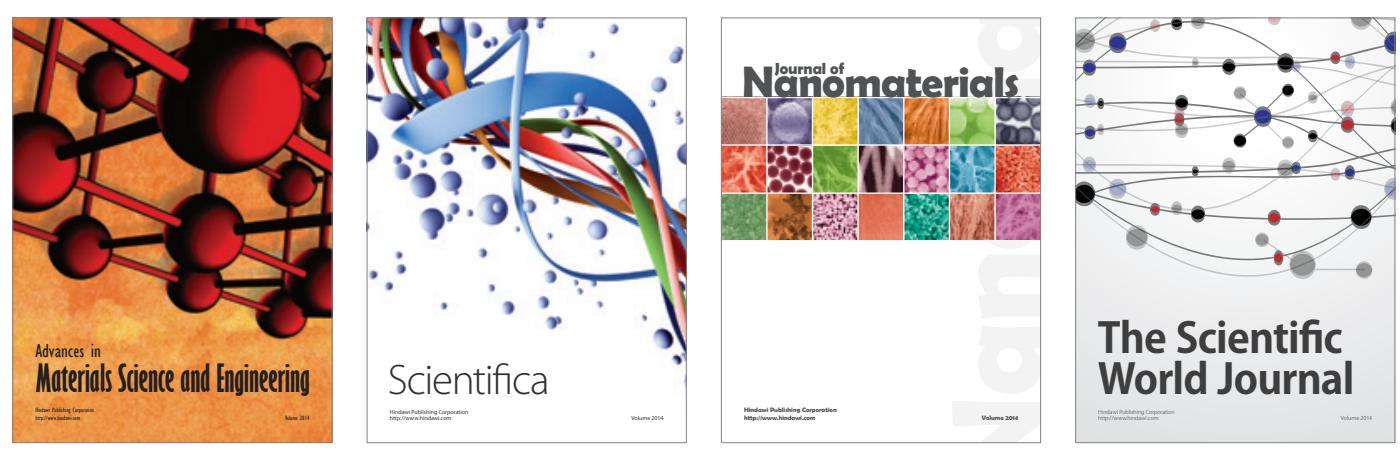

\section{The Scientific World Journal}
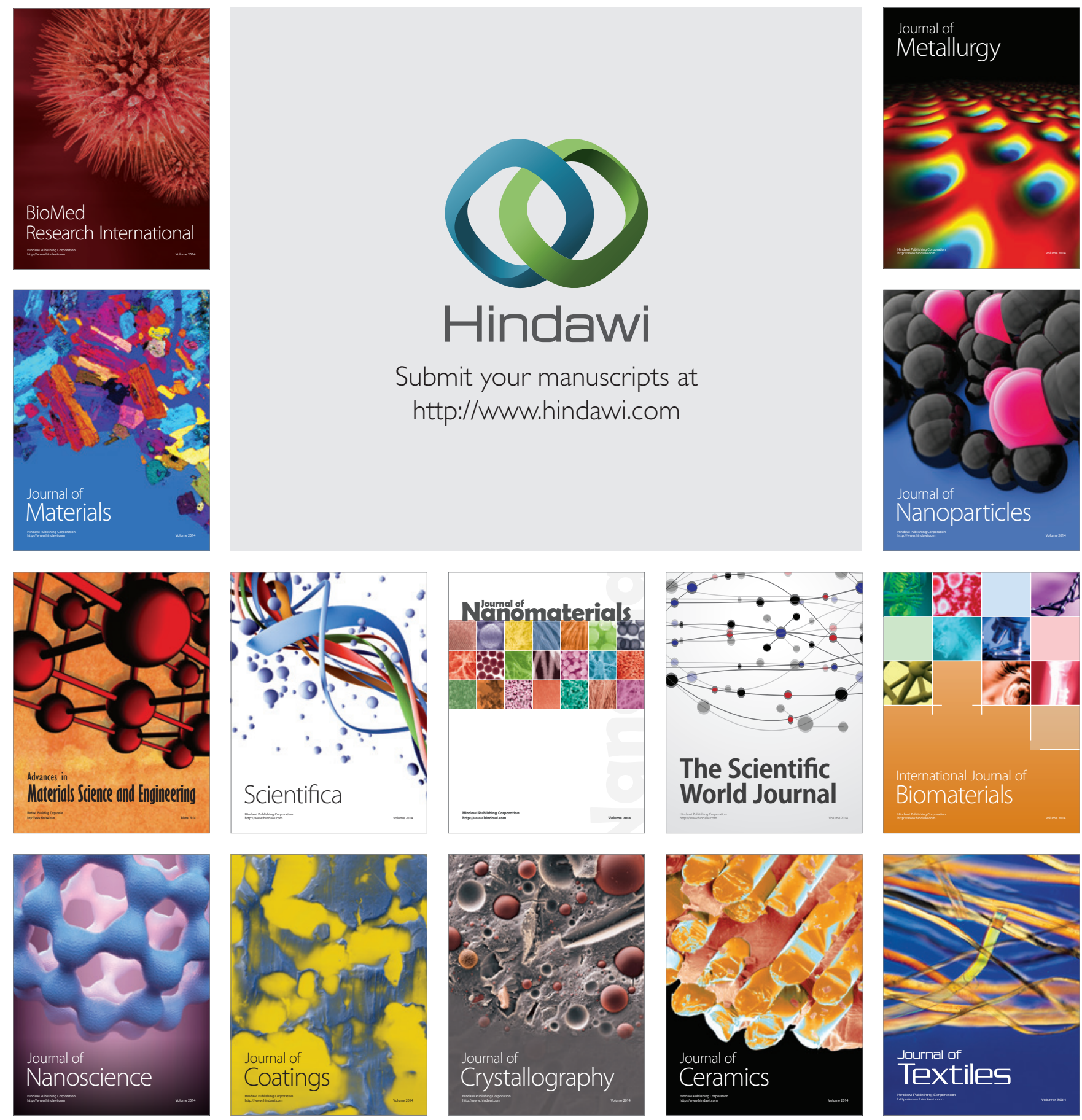